\title{
AFETIVIDADE NA ESCOLA: ALTERNATIVAS TEÓRICAS E PRÁTICAS*
}

\author{
Mário Sérgio Vasconcelos
}

$\mathcal{N}$

ão é recente a discussão sobre o papel da afetividade na constituição da subjetividade humana. Inserida na história da filosofia, no contexto das relações entre razão emoção e sentimento, foi motivo de aquecidos debates envolvendo grandes filósofos, que ora valorizavam os conflitos existentes entre razão e sentimentos, ora a dicotomia ou o papel superior de um aspecto sobre o outro. Eurípedes, por exemplo, investia no tema do conflito entre razão e emoção e freqüentemente ilustrava esse aspecto em suas peças teatrais. ${ }^{1}$ Já Aristóteles, numa perspectiva claramente dualista, reiterava que os sentimentos residem no coração e que o cérebro tem a missão de esfriar o coração e os sentimentos nele localizados. Kant, destacando a supremacia da razão, construiu uma perspectiva negativa das emoções e dos sentimentos, chegando a afirmar que as paixões são a enfermidade da alma. De um modo geral, o que se evidencia nos escritos dos filosóficos, da Grécia antiga até a modernidade, é uma concepção dissociada, na qual a razão quase sempre tem status superior com relação aos sentimentos.

$\mathrm{Na}$ história da psicologia, iniciada no séc. XIX, o cenário não foi muito diferente. Depois que o comportamento humano foi considerado sujeito a princípios universais e que se admitiu a ciência psicológica como possível, alguns dos problemas filosóficos foram transferidos para a psicologia. Porém, foram formulados de tal maneira que se tornou difícil resolvê-los "cientificamente", pois voltou à cena a divisão entre razão e emoção. Theodor Fechner, um dos precursores da ciência psicológica, na

\footnotetext{
* Resenha do livro organizado por Valéria Amorim Arantes, Afetividade na escola: alternativas teóricas e práticas (São Paulo: Summus Editorial, 2003. 237p. Coleção na Escola: alternativas teóricas e práticas).

** Doutor em Psicologia Escolar pela Universidade de São Paulo (USP), pós-doutorado em Processos Cognitivos pela Universidade de Barcelona e professor do Programa de Pós-Graduação em Psicologia da Universidade Estadual Paulista (UNESP/Assis). E-mail: vascon@assis.unesp.br
} 
obra Elemente der Psychophisik, escrita em 1860, declarou que estava interessado na ciência exata das relações funcionais entre razão e emoção. Porém, argumentava que, para fazer ciência, era necessário medir separadamente os dois aspectos. Alguns anos depois Fechner até tentou demonstrar a identidade dessas "duas metades", mas encontrou resistências de vários psicólogos à sua tentativa de unir algo que os filósofos, utilizando métodos racionalistas, tinham separado há centenas de anos.

Tal cisão foi mantida intocável até o início do século XX, pois o movimento dessas dicotomias ganhou força em diferentes áreas e culminou numa discussão quase inconciliável entre os sistemas teóricos empiristas e inatistas que dominaram o cenário dos debates sobre conhecimento, pensamento, comportamento e sentimentos humanos. Os empiristas "cuidaram" da razão e os inatistas da emoção. Posteriormente, com a consolidação de grandes teorias psicológicas como a gestalt, a psicanálise, o behaviorismo, a epistemologia genética, a psicologia cultural e a psicologia sócio-histórica, o problema passa a ser debatido de modo mais aprofundado por cada modelo e começam a aparecer estudos sobre as relações entre cognição e afetividade. Mesmo assim, aos olhos do consumo, cada teoria acabou se dedicando mais a um aspecto que ao outro. Além disso, algumas teorias, como, por exemplo, o behaviorismo, insistiram em continuar alimentando uma distinção radical entre cognição e afetividade. Desse modo, mesmo no campo da psicologia, ainda hoje persiste a idéia de que cognição e afetividade são instâncias dissociadas.

$\mathrm{Na}$ área educacional o trajeto também não foi e não é muito diferente. É comum, ainda hoje, no âmbito escolar, o uso de uma concepção teórica que leva os educadores a dividirem a criança em duas metades: a cognitiva e a afetiva. Esse dualismo é um dos maiores mitos presentes na maioria das propostas educacionais da atualidade. A crença nessa oposição faz com que se considere o pensamento calculista, frio e desprovido de sentimentos, apropriado para a instrução das matérias escolares clássicas. Acredita-se que apenas o pensamento leve o sujeito a atitudes racionais e inteligentes, cujo expoente máximo é o pensamento científico e lógico-matemático. Já os sentimentos, vistos como "coisas do coração", não levam ao conhecimento e podem provocar atitudes irracionais. Produzem fragilidades de segundo plano, próprias da privacidade "inata" de cada um. Seguindo essa crença, as instituições educacionais caminharam para a ênfase da razão, priorizando tudo o que se relaciona diretamente ao mérito intelectual. 
O fato é que estamos no século XXI e o uso técnico especializado do dualismo razão e emoção segue vivendo sobre o prisma do dualismo cognição e afetividade. No entanto, parecem surgir luzes no fim do túnel. E, neste sentido, o livro Afetividade na escola: alternativas teóricas e práticas, organizado por Valéria Amorim Arantes, vem a calhar.

Rapidamente o leitor que se debruçar sobre a obra perceberá um conjunto de abordagens variadas, mas com um aspecto comum que une os 11 textos que a compóem: o fato de autores e autoras questionarem os tradicionais dualismos do pensamento ocidental e compartilharem da premissa de que cognição e afetividade são dimensões indissociáveis no funcionamento psíquico humano.

A passagem por cada um dos textos revela que continua sendo fascinante debater os mistérios que envolvem a afetividade. Os primeiros cinco artigos estão voltados para a análise das relações entre cognição e afetividade a partir de teorias clássicas da psicologia. Marta Khol de Oliveira e Teresa Cristina Rego navegam à luz dos pressupostos vygostskianos e discorrem sobre o papel da afetividade no processo de construção cultural da significação. Maria Cristina Machado Kupfer, sob a ótica da psicanálise, elege um debate provocativo ao afirmar que a psicanálise não trata do desenvolvimento afetivo, mas sim das representações inconscientes. Nessa perspectiva, passando pela discussão da difícil aliança entre os pressupostos piagetianos e freudianos, tece comentários sobre como a história da constituição do sujeito pode interferir no desenvolvimento cognitivo. Maria Thereza Costa Coelho de Souza faz uma leitura das discussões efetuadas por Piaget sobre as relações entre inteligência e afetividade no decorrer das distintas etapas de desenvolvimento humano. Isabel Galvão, explorando a teoria psicogenética de Henry Wallon, aborda seus estudos sobres as expressóes emocionais e postula a indissociabilidade entre os processos afetivos e os cognitivos, propondo uma ressignificação das práticas pedagógicas. No quinto artigo, Maria Isabel da Silva Leme destaca as relações entre cognição e afetividade do ponto de vista da psicologia cultural. Neste sentido, postula que cognição e afetividade são instâncias constituídas culturalmente.

Os quatro textos seguintes elegem o campo da moralidade humana e da ética como eixo principal para discutir as relações entre cognição, afetividade e cultura. Valéria Amorim Arantes, após uma breve retrospectiva das principais correntes da psicologia moral e subsidiada por pesqui- 
sa empírica, apresenta suas reflexões na perspectiva dos modelos organizadores do pensamento. Finaliza apontando algumas implicações educacionais decorrentes da articulação dialética entre os aspectos afetivos, cognitivos e sociais que compōem a subjetividade. Genoveva Sastre e Montserrat Moreno, docentes da Universidade de Barcelona, apresentam uma proposta ousada para a educação e ressaltam a necessidade de se redefinir os princípios curriculares no sentido de contemplar a realidade psíquica diversa e complexa de alunos e alunas. Defendendo a proposta de uma educação que rompa com as fronteiras entre o científico e o cotidiano, indicam a metodologia de resolução de conflitos como estratégia possível de humanização do conhecimento. Ulisses Araújo, procurando avançar nas discussões sobre as relações entre emoções, sentimentos e afetividade, busca suporte nos estudos neurológicos de Antonio Damásio e descreve um modelo explicativo para a complexidade da mente humana. Conclui suas reflexões com uma proposta de reorganização dos espaços educativos tendo como eixo a construção de valores. $\mathrm{O}$ nono texto do livro, de Elizabeth Harkot-de-La-Taille, traz uma reflexão sobre valores e ações morais considerando os estereótipos culturais da sociedade. Sua abordagem inclui o medo e a vergonha como reguladores da ação humana. Preconizando o ideal de felicidade, apresenta uma proposta que releva a idéia de um projeto de vida ético articulado com a força da liberdade humana.

Finalmente, os dois últimos textos percorrem, respectivamente, o campo da neurologia e da epistemologia. O neurologista Antoine Bechara, docente da Universidade de Iowa, discorre sobre o papel positivo da emoção na cognição, procurando evidenciar que o processo de tomada de decisões depende dos substratos neurais que regulam as emoções e os sentimentos. No último capítulo, Nílson José Machado busca uma síntese entre os ideais de objetividade e subjetividade na construção do conhecimento. Perpassa pelas idéias de Popper e Polanyi e promove uma discussão epistemológica que recupera os "lugares" do sujeito, da pessoa e do cidadão.

Para todos os autores que participam do livro, despontam como foco de análise novos paradigmas e a superação de rupturas clássicas que marcaram o trajeto da filosofia, da psicologia e da educação. As idéias expostas indicam um caminhar atual, ou por que não dizer, com sentido indissociado, uma racionalização apaixonada, portanto afetiva, sobre o assunto. Por isso, a travessia dos textos vai nos chamando a perce- 
ber que a sustentação da polarização entre afetividade e cognição, em vários campos, contém fortes contradições. Principalmente no âmbito escolar, do qual os afetos estão excluídos. É hora de desvelá-las e promover a inclusão dos afetos. Tal fato representa uma viagem desafiadora. Foi dada a partida e, para avançar no trajeto, fica o convite para que os educadores comecem com uma simples indagação: Se no campo educacional os afetos continuam sendo tão problemáticos para o conhecimento, não seria uma ingenuidade ignorá-los?

\section{Nota}

1. Medéia, talvez sua personagem mais famosa, na iminência de matar os filhos, exclama: "Sei que crimes vou cometer, mas a cólera é mais forte que minha vontade". Eurìpedes, Médée, Théatre Complet, v. IV, Paris: Garnier Flamarion, 1966, p. 149. 